\title{
Osteometabolic and Osteogenetic Pattern of Turkish Immigrants in Germany
}

\author{
Authors \\ Affiliations \\ Key words \\ - bone mineral density \\ osteoporosis \\ vitamin D deficiency \\ vitamin D receptor \\ polymorphism \\ - lactase polymorphism
}

I. H. Tarner ${ }^{1 *}$, M. Z. Erkal ${ }^{*}$, B. M. Obermayer-Pietsch ${ }^{3}$, L. C. Hofbauer ${ }^{4}$, S. Bergmann ${ }^{5}$, C. Goettsch ${ }^{4}$ K. Madlener ${ }^{6}$, U. Müller-Ladner ${ }^{1}$, U. Lange $^{1,7}$

Affiliation addresses are listed at the end of the article received 25.04.2012

first decision 25.04.2012

accepted 28.06.2012

\section{Bibliography}

DOI http://dx.doi.org/

10.1055/s-0032-1321808

Published online:

September 6, 2012

Exp Clin Endocrinol Diabetes

2012; 120: 517-523

(C) J. A. Barth Verlag in

Georg Thieme Verlag KG

Stuttgart · New York

ISSN 0947-7349

\section{Correspondence}

\section{Prof. Dr. U. Lange, MD}

Professorship of Rheumatology,

Osteology and Physical

Medicine

Department of Internal

Medicine

Justus-Liebig-University Giessen Department of Rheumatology,

Clinical Immunology, Osteology and Physical Medicine

Kerckhoff-Klinik

Benekestraße 2-8

D-61231 Bad Nauheim Germany

Tel.: +49/6032/996 2100

Fax: +49/6032/996 2104

u.lange@kerckhoff-klinik.de

\section{Abstract}

$\nabla$

Introduction: The etiology of osteoporosis comprises environmental and genetic factors. This study investigated vitamin D deficiency and specific genetic alterations of bone metabolism in a group of 183 Turkish immigrants in Germany in comparison with 46 age and sex matched healthy German controls (females in both groups were pre-menopausal).

Methods: Bone mineral density (BMD) was measured by dual-energy X-ray absorptiometry. Serum levels of osteologic parameters were determined after overnight fasting. Polymorphisms of the vitamin D receptor (VDR) and lactase genes were genotyped using genomic DNA from peripheral leukocytes. Statistical analysis comprised student's t-test, Mann-Whitney rank sum test, Chi-square analysis and Fisher's exact test.

Results: Severe 25-OH $\mathrm{D}_{3}$ hypovitaminosis (83.1\%) and elevated parathyroid hormone (82\%) were common among immigrants. Osteoporosis

\section{Introduction}

\section{$\nabla$}

Vitamin D status is highly different in various countries of Europe, the Middle East and Asia and a well known problem especially during the winter time [1,2]. A north-south gradient was observed for 25-OH vitamin $\mathrm{D}_{3}$ with higher levels in Scandinavia and lower levels in Italy, Spain, and some Eastern European countries. This observation points to other determinants than sunshine, e.g., nutrition, food fortification and supplement use. Very low levels of 25-OH vitamin $D_{3}$ have been reported in the Middle East, e.g., Turkey, Lebanon, Jordan and Iran [1,3]. Therefore, in Europe immigrants from these countries inherit a high risk of vitamin D defi-

*I. H. Tarner and M. Z. Erkal contributed equally to this study. but not osteopenia was more prevalent in immigrants. Among immigrants with osteoporosis, TRAP5b was elevated in $26.7 \%$, and $\beta$-crosslaps in $13.3 \%$. Only the FokI FF VDR-gene-polymorphism was significantly more prevalent among immigrants. In contrast, Ff-genotyped Turkish women exhibited significantly decreased BMD. Lactase polymorphisms were significantly more common among immigrants (84.2\% vs. $30.4 \%$ ) and the CC genotype was commonly associated with reduced BMD (41.6\%) but rarely osteoporosis (8.4\%).

Conclusions: Vitamin D deficiency, secondary hyperparathyroidism and osteoporosis are common among Turkish immigrants in Germany. Thus, in this population osteologic parameters and BMD should be analyzed and deficiencies be treated. Specifically, the VDR gene polymorphism FokI Ff is of clinical value in identifying females at risk of osteoporosis. In contrast, LCT polymorphisms, though common, do not appear to be a risk factor.

ciency and subsequent severe clinical musculoskeletal problems [4,5]. Severe vitamin D deficiency causes rickets (defect of mineralization affecting the growing skeleton) or osteomalacia (abnormal mineralization of the mature skeleton) and bone loss (osteopenia/osteoporosis). Less severe vitamin D deficiency causes an increase of serum parathyroid hormone (PTH) leading to bone resorption, osteoporosis and fractures (secondary hyperparathyroidism) [6-8]. The major cause of osteomalacia is vitamin $\mathrm{D}$ deficiency, which is most often due to reduced cutaneous production of vitamin D in housebound elderly people, immigrants to Northern countries and women who obey strict dress codes which prohibit exposure of uncovered skin $[4,9,10]$. 
The etiology of osteoporosis is multi-factorial and caused by both environmental and genetic factors. As a possible genetic component of osteoporosis, an association between bone mineral density (BMD), calcium absorption and polymorphisms of the vitamin D receptor gene (VDR) has been reported $[11,12]$. Lactase deficiency is a common autosomal recessive condition resulting in decreased intestinal lactase degradation. A 13910 $\mathrm{T} / \mathrm{C}$ dimorphism (LCT) near the lactase phlorizin hydrolase gene, reported to be strongly associated with adult lactase non-persistence, may also have an impact on calcium supply, and subsequently on bone metabolism and bone mineral density [3,13-15].

In a recent study, we found a high prevalence of vitamin D deficiency, secondary hyperparathyroidism and generalized bone pain in Turkish immigrants living in Germany [4]. However, precise data about the described parameters that influence bone metabolism and bone mineral density are scarce in this population. To elucidate potential causative factors for alteration of bone metabolism we performed a cross-sectional study that investigated Turkish immigrants living in Germany, who were compared to a group of healthy Germans. To our knowledge, this is also the first report, in which the prevalence of vitamin D deficiency, secondary hyperparathyroidism, loss of bone mineral density, markers of bone metabolism and genetically defined lactose maldigestion, and polymorphism of the vitamin D receptor gene in Middle East immigrants to a central European country was examined.

\section{Patients and Methods}

$\nabla$

\section{Study population}

To exclude short-term effects on bone metabolism (e.g., by migration stress), the study population comprised 183 Turkish immigrants living in Germany for more than 5 years (98 males, 85 females, mean age 40.96 years) and 46 age and sex matched healthy Germans. All women were premenopausal with a physiological sexual hormone status. In addition, participants with inflammatory bowel disease, malabsorption, liver disease, hypophosphatemia, tubular dysfunction and anticonvulsive therapy were excluded from the study. To minimize short-term effects of nutrition and sunlight exposure, the he study period was limited to March and April 2008.

\section{Laboratory parameters}

Phlebotomy was performed in the morning after an overnight fasting period. Blood samples for plasma separation were collected in EDTA-containing tubes and centrifuged immediately $(<1 / 2 \mathrm{~h}$ after phlebotomy). Serum tubes were centrifuged after clotting and total serum calcium concentration $\left(\mathrm{sCa}^{2+}\right.$, reference range $2.15-2.55 \mathrm{mM} / \mathrm{l}$ ), phosphate $(\mathrm{P}$, reference range $0.87-1.45 \mathrm{mM} / \mathrm{l}$ ), alkaline phosphatase (AP, reference range $35-129 \mathrm{U} / \mathrm{L}), 25-\mathrm{OH}$ vitamin $\mathrm{D}_{3}\left(25-\mathrm{OH} \mathrm{D}_{3}\right.$, reference range $30-60 \mathrm{ng} / \mathrm{ml}$; Incstar Corporation, Stillwater, MN, USA), parathyroid hormone (PTH, reference range $8.3-68 \mathrm{pg} / \mathrm{ml}$; PTH intact ELISA, DRG Instruments GmbH, Marburg, Germany), osteocalcin (OC, reference range males: $12-51.1 \mathrm{ng} / \mathrm{ml}$, females 6.5-42.3 ng/ $\mathrm{ml}$; LIAISON Osteocalcin, DiaSorin Inc, Stillwater, MN, USA), $\beta$-crosslaps (CL, reference range males: $30-50$ years $<0.584 \mathrm{ng} /$ $\mathrm{ml}, 50-70$ years $<0.704 \mathrm{ng} / \mathrm{ml}$; premenopausal females: $<0.573 \mathrm{ng} /$ $\mathrm{ml} ; \beta$-crosslaps/serum, Roche Diagnostics, Indianapolis, IN, USA), and tartrate-resistant acid phosphatase isoform $5 \mathrm{~b}$ (TRAP5b, refer- ence range males: $4.0 \pm 1.4 \mathrm{U} / \mathrm{l}$, females $2.9 \pm 1.4 \mathrm{U} / \mathrm{l}$; Metra TRAP5b EIA Kit, Quidel Corporation, San Diego, CA, USA), were batch analyzed in serum samples.

\section{Genotyping}

Genomic DNA was extracted from samples of peripheral venous blood. Single nucleotide polymorphism (SNP) genotyping was performed using a microplate fluorometer (Fluoroskan Ascent, Thermo Fisher Scientific, Waltham, MA, USA). Identification of C/T exchanges was carried out by an allele-specific polymerase chain reaction (PCR) (Amplifluor SNPs HT Genotyping System FAM-SR; Serologicals Corporation, Norcross, GA, USA) as described previously [16]. The polymorphic site was amplified by using the sequence $5^{\prime}$-GTTCCTTTGAGGCCAGGGA-3' as specific primer for LCT-T and the sequence 5 '-TTCCTTTGAGGCCAGGGG-3' as specific primer for LCT-C. PCR and VDR FokI- and Bsml-genotyping were performed as described previously $[17,18]$. Alleles were genotyped for the presence $(\mathrm{f}, \mathrm{b})$ or the absence (F, B) of the FokI or BsmI restriction sites, respectively.

\section{Osteodensitometry}

BMD $\left(\mathrm{g} / \mathrm{cm}^{2}\right)$ was measured at the lumbar spine (first to fourth vertebrae, antero-posterior view) and the total right femur by dual-energy X-ray absorptiometry (DXA; Prodigy Lunar, Milwaukee, Wisconsin, USA). The coefficient of variation of repeated measurements in vivo was $0.9 \%$ for the lumbar spine and $1.6 \%$ for the femur. T-score (number of standard deviations (SD) from the normal mean obtained from young healthy adults) and Z-score (number of SD from the mean of age- and sex-matched controls) were also calculated. A low BMD was defined according to the world health organization (WHO) guidelines: Osteopenia as a T-score between -1 and $-2.5 \mathrm{SD}$ and osteoporosis as a $\mathrm{T}$ score $<-2.5 \mathrm{SD}$. The respective reference values have been published previously for women and men. For the purpose of this study, the reference values of the manufacturer were used.

\section{Ethical approval}

The study was approved by the local Ethics Committee of the Faculty of Medicine, Justus-Liebig-University, Giessen, Germany, and all study participants gave written informed consent prior to inclusion into the study.

\section{Statistical analysis}

All data are presented as mean \pm SD. Data were tested for normality by the Kolmogorov-Smirnov test. For comparison of the groups, numeric values (e.g., age) were analyzed by Student's t-test. Data that showed unequal variance or abnormal distribution were analyzed by the Mann-Whitney rank sum test. Proportions of the groups were compared by Chi-square analysis and Fisher's exact test. A p value of $<0.05$ was regarded as significant for all analyses. Data were evaluated using SPSS Release 12.0.1 (SPSS Inc., Chicago, IL, USA).

\section{Results \\ $\nabla$}

\section{Vitamin D metabolism and other laboratory} parameters

Basic demographic and osteologic data of the patient groups are shown in $\odot$ Table 1. Both groups did not differ in age, lumbar and femoral BMD (including T- and Z-scores) as well as serum levels of AP and CL. Significantly higher mean values were found 
Table 1 Demographic data and results of bone-specific characteristics of Turkish immigrants and German controls. Values shown are mean \pm standard deviation; reference ranges are given in brackets. Level of significance (Mann-Whitney-U-test) for difference between the 2 populations: $p<0.05$.

\begin{tabular}{|c|c|c|c|}
\hline Parameter & $\begin{array}{l}\text { Turkish immigrants } \\
(\mathrm{n}=183)\end{array}$ & $\begin{array}{l}\text { German controls } \\
(n=46)\end{array}$ & p-value \\
\hline age (years) & $40.96 \pm 10.39$ & $39.67 \pm 13.18$ & 0.339 \\
\hline BMI $\left(\mathrm{kg} / \mathrm{m}^{2}\right)$ & $28.16 \pm 4.53$ & $25.29 \pm 4.54$ & $<0.0005$ \\
\hline BMD L1-4 $\left(\mathrm{g} / \mathrm{cm}^{2}\right)$ & $1.16 \pm 0.17$ & $1.17 \pm 0.14$ & 0.581 \\
\hline T-score L1-4 & $-0.34 \pm 1.45$ & $-0.15 \pm 1.14$ & 0.363 \\
\hline Z-score L1-4 & $-0.37 \pm 1.38$ & $-0.27 \pm 1.16$ & 0.486 \\
\hline BMD right femur $\left(\mathrm{g} / \mathrm{cm}^{2}\right)$ & $1.04 \pm 0.12$ & $1.03 \pm 0.14$ & 0.626 \\
\hline T-score right femur & $-0.04 \pm 0.99$ & $0.05 \pm 1.07$ & 0.837 \\
\hline Z-score right femur & $0.07 \pm 0.89$ & $0.01 \pm 0.96$ & 0.728 \\
\hline $25-\mathrm{OH} \mathrm{D}_{3}(30-60 \mathrm{ng} / \mathrm{ml})$ & $8.85 \pm 9.90$ & $21.86 \pm 24.25$ & $<0.0005$ \\
\hline PTH $(8.3 n-68 p g / m l)$ & $109.44 \pm 42.54$ & $58.48 \pm 12.75$ & $<0.005$ \\
\hline AP (35-129U/L) & $64.81 \pm 19.78$ & $59.74 \pm 16.65$ & 0.098 \\
\hline Phosphate $(0.87-1.45 \mathrm{mmol} / \mathrm{I})$ & $1.10 \pm 0.18$ & $1.20 \pm 0.1$ & $<0.0005$ \\
\hline $\mathrm{sCa}{ }^{2+}(2.15-2.55 \mathrm{mmol} / \mathrm{l})$ & $2.33 \pm 0.14$ & $2.39 \pm 0.14$ & 0.005 \\
\hline CL (males, $30-50$ years: $<0.548 \mathrm{ng} / \mathrm{ml}$; males, $50-70$ years: $<0.704 \mathrm{ng} / \mathrm{ml}$; females: $<0.573 \mathrm{ng} / \mathrm{ml}$ ) & $0.35 \pm 0.18$ & $0.41 \pm 0.21$ & 0.071 \\
\hline OC (males: $12-51.1 \mathrm{ng} / \mathrm{ml}$; females: $6.5-42.3 \mathrm{ng} / \mathrm{ml}$ ) & $14.25 \pm 4.86$ & $16.91 \pm 7.89$ & 0.034 \\
\hline TRAP5b (males: $4.0 \pm 1.4 \mathrm{U} / \mathrm{l}$; females: $2.9 \pm 1.4 \mathrm{U} / \mathrm{I}$ ) & $2.13 \pm 1.07$ & $2.75 \pm 1.15$ & 0.001 \\
\hline
\end{tabular}

Table 2 Total number (percent) of Turkish immigrants exhibiting pathological changes of biochemical markers of bone metabolism in comparison with German controls. An elevated value for TRAP5b is defined as exceeding the shown mean \pm standard deviation.

\begin{tabular}{|c|c|c|}
\hline Parameters & Turkish immigrants $(n=183)$ & German controls $(n=46)$ \\
\hline \multicolumn{3}{|l|}{$25-\mathrm{OH} \mathrm{D}_{3}$} \\
\hline vitamin D sufficiency ( $\geq 30 \mathrm{ng} / \mathrm{ml}$ ) & $4(2.2 \%)$ & $25(54.3 \%)$ \\
\hline \multicolumn{3}{|l|}{ hypovitaminosis: } \\
\hline mild vitamin D insufficiency (20-29.9 ng/ml) & $9(4.9 \%)$ & $21(45.7 \%)$ \\
\hline moderate vitamin D deficiency $(10-19.9 \mathrm{ng} / \mathrm{ml})$ & $18(9.8 \%)$ & 0 \\
\hline severe vitamin D deficiency (<10 ng/ml) & $152(83.1 \%)$ & 0 \\
\hline reduced OC (males: < $12 \mathrm{ng} / \mathrm{ml}$; females: $6.5 \mathrm{ng} / \mathrm{ml}$ ) & $21(11.5 \%)$ & $3(6.5 \%)$ \\
\hline elevated TRAP5b (males: $>4.0 \pm 1.4 \mathrm{U} / \mathrm{l}$; females: $>2.9 \pm 1.4 \mathrm{U} / \mathrm{I}$ ) & $14(7.7 \%)$ & $4(8.7 \%)$ \\
\hline $\begin{array}{l}\text { elevated CL (males, } 30-50 \text { years }>0.548 \mathrm{ng} / \mathrm{ml} \text {; males, } 50-70 \text { years: }>0.704 \mathrm{ng} / \mathrm{ml} \text {; } \\
\text { females: }>0.573 \mathrm{ng} / \mathrm{ml} \text { ) }\end{array}$ & $23(12.6 \%)$ & $8(17.4 \%)$ \\
\hline elevated PTH (>68 pg/ml) & $150(82 \%)$ & $37(80.4 \%)$ \\
\hline elevated AP (>129U/L) & $12(6.6 \%)$ & 0 \\
\hline
\end{tabular}

in the Turkish group for body mass index (BMI), and PTH levels. In contrast, the serum levels of calcium, phosphate, $25-\mathrm{OH} \mathrm{D}_{3}$, OC and TRAP5b were significantly reduced.

Specifically, the vast majority of Turkish immigrants presented with a vitamin $\mathrm{D}$ deficiency. A severe vitamin D deficiency (25$\mathrm{OH} \mathrm{D}_{3}<10 \mathrm{ng} / \mathrm{ml}$ ) was found in $83.1 \%$, vs. $0 \%$ of the Germans, a moderate vitamin D deficiency $\left(25-\mathrm{OH} \mathrm{D}_{3} 10-19.9 \mathrm{ng} / \mathrm{ml}\right)$ in $9.8 \%$ vs. $0 \%$ of the Germans, and a mild vitamin D insufficiency (25-OH D $20-29.9 \mathrm{ng} / \mathrm{ml})$ in $4.9 \%$ vs. $45.7 \%$ of the Germans ( $\bullet$ Table 2). By contrast, sufficient levels of vitamin D were only seen in $2.2 \%$ of Turkish immigrants vs. $54.3 \%$ of the Germans ( Table 2). No gender-specific differences were observed for all parameters. Furthermore, Turkish immigrants had decreased levels of osteocalcin in $11.5 \%$, elevated levels of PTH in $82 \%$, of TRAP5b in $7.7 \%$, of CL in $12.6 \%$, and of AP in 6.6\% (॰ Table 2). An additional regression analysis of the parameters did not show a significant dependence.

Of note, although vitamin D deficiency was highly prevalent in the Turkish group, the typical laboratory constellation of secondary hyperparathyroidism (increased $\mathrm{PTH}$, decreased $\mathrm{sCa}^{2+}$ ) was observed only in 12 cases with a predominance of females (10 females, 2 males). This prevalence of secondary hyperparathyroidism (6.6\%) did not differ from the German group (6.5\%). Furthermore, none of these Turkish individuals had osteoporosis, and only one of them presented with osteopenia. Phosphate levels were decreased in 7 cases, but only one of them had a true vitamin D hypovitaminosis.

\section{BMD and bone metabolism parameters}

An alteration of BMD was seen in Turkish immigrants in $40.2 \%$. Osteoporosis was observed in 15 cases (8.2\%), osteopenia in 59 cases (32.2\%; — Table 3a), whereas the German controls showed no osteoporosis and osteopenia was observed in 17 cases (37\%; Table 3b). There was no gender-specific preference in either group. Turkish immigrants with osteoporosis were significantly older than immigrants with osteopenia $(50.5 \pm 11.4$ years vs. $39.8 \pm 8.7$ years, $\mathrm{p}<0.002$ ). The incidence of severe vitamin D deficiency $\left(25-\mathrm{OH} \mathrm{D}_{3}<10 \mathrm{mg} / \mathrm{ml}\right)$ was identical in the groups with osteoporosis and osteopenia, respectively ( $\bullet$ Table 3a), whereas the Germans with osteopenia did not exhibit severe vitamin D deficiency ( $\bullet$ Table $\mathbf{3 b}$ ). Osteoporosis in Turkish immigrants was more frequently associated with reduced OC and elevated AP levels than osteopenia ( $\bullet$ Table 3a).

\section{Genetic pattern}

Turkish immigrants showed a significant predominance $(54.1 \%$, $\mathrm{p}=0.009$; Table 4) of the FokI genotype FF. Apart from that, there were no significant differences in the distribution of the BsmI- and Fok I polymorphisms of the VDR-gene between Turkish immigrants and Germans. 
Table 3 Comparison of the prevalence of pathological changes in biochemical markers of bone metabolism between osteopenia and osteoporosis in Turkish immigrants (A) and German controls (B). An elevated value for TRAP5b is defined as exceeding the shown mean \pm standard deviation.

A

Parameter

severe $25-\mathrm{OH} \mathrm{D}_{3}$ deficiency $(<10 \mathrm{mg} / \mathrm{ml})$

reduced OC (males: $<12 \mathrm{ng} / \mathrm{ml}$; females: $<6.5 \mathrm{ng} / \mathrm{ml}$ )

elevated TRAP5b (males: $>4.0 \pm 1.4 \mathrm{U} / \mathrm{l}$; females: $>2.9 \pm 1.4 \mathrm{U} / \mathrm{l}$ )

elevated CL (males, $30-50$ years: $>0.548 \mathrm{ng} / \mathrm{ml}$; males, $50-70$

years: $>0.704 \mathrm{ng} / \mathrm{ml}$; females: $>0.573 \mathrm{ng} / \mathrm{ml})$

elevated AP (>129U/L)

elevated PTH $(>68 \mathrm{pg} / \mathrm{ml})$

B

Parameter

severe $25-\mathrm{OH} \mathrm{D}_{3}$ deficiency $(<10 \mathrm{mg} / \mathrm{ml})$

reduced OC (males: $<12 \mathrm{ng} / \mathrm{ml}$; females: $<6.5 \mathrm{ng} / \mathrm{ml}$ )

elevated TRAP5b (males: $>4.0 \pm 1.4 \mathrm{U} /$ l; females: $>2.9 \pm 1.4 \mathrm{U} / \mathrm{I}$ )

elevated $\mathrm{CL}$ (males, $30-50$ years: $>0.548 \mathrm{ng} / \mathrm{ml}$; males, $50-70$

years: $>0.704 \mathrm{ng} / \mathrm{ml}$; females: $>0.573 \mathrm{ng} / \mathrm{ml}$ )

elevated AP (>129U/L)

elevated PTH $(>68 \mathrm{pg} / \mathrm{ml})$

Table 4 Distribution of VDR-polymorphisms in Turkish immigrants and German controls.

\begin{tabular}{|lll}
$\begin{array}{l}\text { VDR Bsml and Fokl } \\
\text { genotypes }\end{array}$ & $\begin{array}{l}\text { Turkish immigrants } \\
(\mathbf{n = 1 8 3 )}\end{array}$ & $\begin{array}{l}\text { German controls } \\
(\mathbf{n = 4 6 )}\end{array}$ \\
\hline BB & $49(26.8 \%)$ & $10(21.7 \%)$ \\
\hline Bb & $62(33.9 \%)$ & $12(26.1 \%)$ \\
\hline bb & $72(39.3 \%)$ & $24(52.2 \%)$ \\
\hline FF & $99(54.1 \%)$ & $16(34.8 \%)$ \\
Ff & $69(37.7 \%)$ & $22(47.8 \%)$ \\
\hline ff & $15(8.2 \%)$ & $8(17.4 \%)$ \\
\hline
\end{tabular}

Table 5 Relation between BMD and VDR Fokl genotypes in pre-menopausal Turkish women. Values shown are mean \pm standard deviation; levels of significance (Fishers-Exact-Test; $\mathrm{p}<0.05$ ) are provided only for the comparison of the FF and Ff genotypes due to the small group size of the ff genotype.

\begin{tabular}{|lcrll} 
& \multicolumn{3}{c}{ Fokl genotype } & p-value \\
& $\mathbf{F F}(\mathbf{n = 5 3})$ & $\mathbf{F f}(\mathbf{n = 3 8 )}$ & $\mathbf{f f}(\mathbf{n}=\mathbf{7})$ & \\
\hline lumbar BMD & $1.19 \pm 0.17$ & $1.11 \pm 0.16$ & $1.23 \pm 0.14$ & 0.046 \\
lumbar T-score & $0.03 \pm 1.43$ & $-0.65 \pm 1.36$ & $0.34 \pm 1.09$ & 0.045 \\
\hline right total femur BMD & $1.05 \pm 0.13$ & $0.98 \pm 0.13$ & $1.06 \pm 0.11$ & 0.033 \\
\hline right total femur T-score & $0.31 \pm 0.99$ & $-0.19 \pm 1.04$ & $0.47 \pm 0.89$ & 0.045
\end{tabular}

Besides, Ff-genotyped Turkish females exhibited significantly decreased BMD and T-Scores of the lumbar spine $(\mathrm{p}<0.046)$ and the right total femur compared with FF-genotyped females ( $\odot$ Table 5). Due to the small group size of ff-genotyped females, the value of a statistical analysis is limited. However, since the mean BMD and T-score values in the ff group were higher than those in the FF group, significance can be inferred. Of note, significant associations with any laboratory parameters could not be demonstrated, and male Turkish immigrants did not show any correlation between BMD and FokI-genotypes.

A genetically determined lactose malabsorption (adult-type hypolactasia; genotype LCT CC) was detected in 154 Turkish immigrants (84.2\%) and in 14 Germans (30.4\%) without genderspecific preference in both groups ( $\bullet$ Table 6 ). Among the immi-

\section{No. (\%) of immigrants with}

$\begin{array}{lc}\text { Osteopenia }(\mathbf{n}=\mathbf{5 9} / \mathbf{1 8 3}) & \text { Osteoporosis }(\mathbf{n}=\mathbf{1 5} / \mathbf{1 8 3}) \\ 47(79.7 \%) & 13(86.7 \%) \\ 3(5.1 \%) & 4(26.7 \%) \\ 10(17.0 \%) & 4(26.7 \%) \\ 10(17.0 \%) & 2(13.3 \%) \\ & \\ 2(3.4 \%) & 8(53.3 \%) \\ 50(84.7 \%) & 10(66.7 \%)\end{array}$

\begin{tabular}{ll}
\multicolumn{1}{c}{ No. (\%) of controls with } \\
Osteopenia $(\mathbf{n = 1 7 | 4 6 )}$ & Osteoporosis $(\mathbf{n = 0 / 4 6 )}$ \\
0 & 0 \\
$2(11.8 \%)$ & 0 \\
$4(23.5 \%)$ & 0 \\
$4(23.5 \%)$ & 0 \\
0 & 0 \\
$13(76.5 \%)$ & 0
\end{tabular}

grants, this genotype was the most frequent one, whereas the TT-genotype was the least frequent one. In contrast, among the Germans, all 3 genotypes were distributed equally. An alteration of bone mineral density was seen in $64(41.6 \%)$ of the immigrants with an LCT CC-genotype: osteopenia in 51 cases (33.2\%) and osteoporosis in 13 cases (8.4\%), also without gender-specific preference. In contrast, 4 of 14 Germans (28.6\%) with an LCT CC-genotype presented an osteopenia, none an osteoporosis. Immigrants with genetically determined lactose malabsorption (LCT CC-genotype) had a significantly higher BMI and significantly decreased levels of TRAP-5b compared with the LCT genotype CT (BMI: $p<0.018$, TRAP-5b: $p<0.047)$ and the German controls (BMI: $p<0.005$, TRAP-5b: $p<0.05$ ), without gender-specific preference. There was no significant association of the LCT genotype with age, $25-\mathrm{OH} \mathrm{D}_{3}$, PTH, AP, phosphate, calcium, crosslaps, osteocalcin, BMD or BsmI-/FokI-polymorphisms in adult-type hypolactasia.

\section{Discussion and Conclusions}

Vitamin D and its metabolites are well-established regulators of bone mineral homeostasis. Their dominant role is the prevention and treatment of rickets and osteomalacia, bone diseases characterized by inadequate bone formation, and mineralization. In vitamin $\mathrm{D}$ deficiency, the major pathological finding observed in bone biopsy is failure of bone to mineralize. Unless not based on a group of genetic syndromes, phosphate wasting or deficiency, or aluminium intoxication, all of which can cause vitamin $\mathrm{D}$ resistance, rickets and osteomalacia can be readily prevented and/or cured by vitamin D replacement. Thus the most common cause of rickets and osteomalacia is vitamin D deficiency, which is an extremely frequent problem in the Middle East, e.g., Turkey, Lebanon, Jordan and Iran [1,2].

The histologic appearance of adult osteomalacia was first described in 1885 but clinical appreciation of the disease took place much later. A large population of adult osteomalacia patients in China provided the basis for a detailed study in the 
Table 6 Distribution of LCT-genotypes in Turkish immigrants and German controls and association with BMI and TRAP-5b levels. Values shown for body mass index (BMI) and tartrate-resistant acid phosphatase isoform 5b (TRAP5b) are mean \pm standard deviation; ${ }^{*} \mathrm{p}<0.047,{ }^{* *} \mathrm{p}<0.018$, vs. genotype CT; \# $\mathrm{p}<0.05$, \#\# p<0.005 vs. German controls. N.D.: not done; LCT: 13910 T/C dimorphism near the lactase phlorizin hydrolase gene.

\begin{tabular}{|c|c|c|c|c|c|c|}
\hline \multirow[t]{2}{*}{ LCT genotypes } & \multicolumn{3}{|c|}{ Turkish immigrants $(n=183)$} & \multicolumn{3}{|c|}{ German controls $(n=46)$} \\
\hline & n (\%) & BMI $\left(\mathrm{kg} / \mathrm{m}^{2}\right)$ & TRAP5b (U/I) & n (\%) & BMI $\left(\mathrm{kg} / \mathrm{m}^{2}\right)$ & TRAP5b (U/I) \\
\hline TT & $2(1.1 \%)$ & N.D. & N.D. & $13(28.3 \%)$ & $25.46 \pm 4.37$ & $2.77 \pm 1.09$ \\
\hline CT & $27(14.8 \%)$ & $26.9 \pm 5.8$ & $2.8 \pm 0.9$ & $19(41.3 \%)$ & $26.15 \pm 5.46$ & $2.77 \pm 1.35$ \\
\hline $\begin{array}{l}\text { CC (adult type } \\
\text { hypolactasia) }\end{array}$ & $154(84.2 \%)$ & $28.4 \pm 4.3^{* *} \# \#$ & $2.1 \pm 1.1^{*} \#$ & $14(30.4 \%)$ & $23.96 \pm 3.06$ & $2.72 \pm 0.98$ \\
\hline
\end{tabular}

1930s. Maxwell estimated that there may have been 100000 cases at that time [19]. In 1948, Albright and Reifenstein reported the presence of osteomalacia in the United States due to lack of vitamin D supplementation [20]. The first report of overt osteomalacia in Turkish immigrants and their offspring in Germany was described in 1978 [21] but there is also evidence for vitamin $\mathrm{D}$ deficiency, secondary hyperparathyroidism and the association with reduced BMD in individuals with Pakistani and Norwegian background living in Oslo, Norway [8]. In addition, Chapuy et al. [22] were the first to propose that a $25-\mathrm{OH} \mathrm{D}_{3}$ level of less than $80 \mathrm{nmol} / \mathrm{l}$ is associated with higher PTH values. In osteomalacia, the main clinical features are bone pain, fractures and muscle weakness.

In a recent study, which to our knowledge is the first detailed analysis and characterization of the prevalence of vitamin $\mathrm{D}$ deficiency, secondary hyperparathyroidism and loss of BMD in Turkish immigrants living in Germany, we found a high prevalence of vitamin D deficiency, secondary hyperparathyroidism and generalized bone pain, particularly in veiled women. Based on these data, we concluded that there is an independent ethnic risk factor for low 25- $\mathrm{OH} \mathrm{D}_{3}$ levels in Turkish nationals compared to Germans. In fact, darker skin pigmentation and cultural differences in clothing in Turkish immigrants, resulting in a reduced ability to synthesize vitamin $\mathrm{D}$ in their skin during sunlight exposure, were identified as risk factors [4].

However, vitamin D metabolism may be influenced by other factors such as age, seasonal sunlight exposure (lower levels between October and April) [23] and also specific genetic alterations. As expected, we found significantly decreased levels of $25-\mathrm{OH} \mathrm{D}_{3}$ in a large proportion of Turkish immigrants (97.8\%; severe $25-\mathrm{OH} \mathrm{D}_{3}$ deficiency in $83.1 \%$ ), although it needs to be considered that the observation period was March/April, i.e., at the end of the winter season with low sunlight exposure. In contrast, $47.3 \%$ of the German controls had abnormal $25-\mathrm{OH} \mathrm{D}_{3}$ levels, but none of them with moderate or severe deficieny. None of the study participants had malabsorption, liver disease, hypophosphatemia, renal tubular dysfunction or received anticonvulsant therapy, which could have induced a vitamin D deficiency.

In vitamin D deficiency, but not necessarily in other causes of osteomalacia, secondary hyperparathyroidism is frequently present. It is well known that even less severe vitamin D deficiency can cause an increase of serum PTH leading to bone resorption, osteoporosis and fractures. Accordingly, in the present study we found elevated PTH levels in $82 \%$ of the Turkish immigrants and $80.4 \%$ of the German controls. However, the mean PTH levels in the Turkish immigrants were significantly higher than in the German controls, which is in keeping with the higher prevalence of severe $25-\mathrm{OH} \mathrm{D}_{3}$ deficiency among the Turks.
Of note, the typical laboratory constellation of a manifest secondary hyperparathyroidism (elevated PTH and decreased calcium levels) was only seen in a small proportion of either group (6.6\% of the Turkish immigrants, $6.5 \%$ of the Germans) with a predominance of women, and there was no association with a reduction in BMD. Therefore, the majority of Turkish immigrants appear to suffer from hypovitaminosis D and incomplete secondary hyperparathyroidism without hypocalcemia, at least for an extended period of time. Most likely, they are able to maintain calcium homeostasis due to a mobilization of calcium from the bone, by gastrointestinal resorption and due to normal kidney function. Interestingly, there was no difference in the extent of $25-\mathrm{OH} \mathrm{D}_{3}$ reduction between Turkish immigrants with and without reduced BMD, although $40.4 \%$ of the cases were found to have either osteopenia (32.2\%) or osteoporosis (8.2\%).

Bone remodeling is characterized by 2 opposing mechanisms, the formation of new bone by osteoblasts and the resorption of aged bone by osteoclasts. Active bone metabolism can be assessed by measuring the enzymatic activity of the osteoblasts and osteoclasts (AP, TRAP5b, crosslaps, osteocalcin).

The AP was found to be elevated in only $6.6 \%$ of the Turkish immigrants, without a significant correlation to BMD. Furthermore, Turkish immigrants had increased TRAP5b levels $(26.7 \%$ of the cases with osteoporosis and $17 \%$ of the cases with osteopenia). Since TRAP5b is released into the serum by bone-resorbing osteoclasts and is an indicator of osteoclast activity, it illustrates overall bone resorption [24]. The crosslaps as biochemical markers of bone resorption were also elevated in Turkish immigrants (in $13.3 \%$ of the cases with osteoporosis and in $17 \%$ of the cases with osteopenia), whereas osteocalcin as a bone formation marker was decreased in $31.9 \%$ (in $26.7 \%$ of the cases with osteoporosis and in $5.2 \%$ of the cases with osteopenia) of the patients. Therefore, the biochemical markers revealed an alteration of the general bone metabolism indicating decreased bone formation and increased bone resorption. Of note, degenerative changes as a possible cause of falsely high BMD values were excluded in immigrants who had moderate to severe vitamin D deficiency and vitamin D insufficiency, respectively, and normal BMD on DXA measurement. In these cases, the osteoprotective estrogen-status in combination with the higher BMI could be the basis for this observation.

Besides environmental factors, there is substantial evidence that genetic factors play also an important role in the multifactorial aetiology of osteoporosis [25]. Several candidate genes have been discussed as being involved in the pathogenesis of osteoporosis. Besides a number of different loci within the vitamin D receptor gene (VDR), such as BsmI polymorphisms at the 3' end region of the VDR [18], FokI polymorphisms in exon 2, the translation initiation codon at the $5^{\prime}$ end of the VDR gene, were defined as functional allelic variants [17] and have been shown 
to be significantly associated with BMD and calcium absorption in several reports $[11,12,17]$.

In the present study, there was no difference in the genetic distribution of the BsmI-polymorphism of the VDR gene neither in Turkish immigrants nor in Germans. However, female Turkish immigrants showed a significant disposition in FokI-polymorphism and Ff-genotyped female Turkish immigrants showed a significantly decreased BMD of the right femur and lumbar spine. There were no associations with any other laboratory parameters.

Calcium has been shown to be an important nutrient in the prevention and treatment of osteoporosis. It is naturally supplied in the form of dairy products that contain lactose. Lactose intolerance has also been shown to reduce dairy intake in affected individuals, due to adult-type hypolactasia and consequent malabsorption. Adult-type hypolactasia, as mediated by a widespread genetic predisposition, not only reduces calcium intake but also calcium absorption in the presence of high amounts of lactose and may, therefore, promote osteoporosis [3-15]. The genetic background of lactose malabsorption (LM) has been described in 2002 by Finnish researchers [26] when a distinct single nucleotide polymorphism (SNP) on chromosome 2q21 was identified (LCT-polymorphism). Individuals homozygous for the $C$ genotype (LCT CC) have almost undetectable levels of intestinal lactase production compared to LCT TC or LCT TT individuals, and present with variable symptoms of lactose malabsorption. There is also a variety of symptoms of LM after ingestion of lactose: abdominal pain, bloating, flatulence, diarrhea, and, particularly in adolescents, vomiting.

The genetic alteration of LM (LCT CC) is common throughout the world with different frequencies: $2 \%$ in Sweden, 20-25\% in Caucasian populations in Europe and the United States, increasing to 60-75\% in South European Caucasians, and 100\% in Southeast Asian population $[13,16,27]$. Analysis of the LCT polymorphism has shown to be a highly reliable tool in the diagnosis of LM. In contrast, conventional diagnostic methods for LM, such as the hydrogen breath test, have a $20 \%$ false negative rate, due to hydrogen non-excretion. The diagnostic sensitivity of the lactose tolerance test is about the same range $[13,15,16]$. The prevalence of LCT-CC in Germans is in line with previous studies [3]. However, in the present study we found a high prevalence of molecular defined lactose malabsorption in Turkish immigrants (84.2\%), but there was no significant association of the LCT CC genotype with BMD and other laboratory parameters or with other specific characteristics (e.g., age, BMI).

This study has several limitations. Bone mineral density can be influenced by several environmental factors such as age, sex, social status, caloric intake and diet composition which can represent confounding factors when analyzing BMD and hypovitaminosis D. When selecting the German controls we did not match them in for all of these aspects with the Turkish immigrants but only for age and sex. Cutural differences in diet composition between Turkish immigrants and Germans can be anticipated even when investigating immigrants who have lived in Germany for several years. The finding of a higher BMI in the Turkish immigrants would be in keeping with this notion. In addition, we limited our osteogenetic analysis to the analysis of polymorphisms of the VDR, the significance of which for primary osteoporosis has been a matter of debate. Furthermore, we did not investigate possible genetic interaction. Thus, a more detailed genetic analysis in larger groups of Turkish and German individuals will be required to further evaluate the genetic basis of bone metabolism and osteoporosis in Turkish immigrants.

In conclusion, vitamin D deficiency, secondary hyperparathyroidism and reduction of the bone mineral density (osteopenia/ osteoporosis) were found to be highly common among Turkish immigrants living in Germany, without showing a gender-specific preference. Since there is an increasing number of Turkish immigrants in Germany, osteomalacia should always be taken into consideration if these individuals develop skeletal pain and muscle weakness. Even minor or vague symptoms should indicate a search for an osteometabolic cause of these sequelae. Moreover, the monitoring of vitamin D status (i.e., $25-\mathrm{OH} \mathrm{D}_{3}$, calcium and PTH) and bone mineral density is warranted and once such a deficiency is identified, it should be treated appropriately. The current screening approach offers a fast, reliable and clinically accurate way for the identification and follow-up of these high-risk patients. Moreover, the early identification and subsequent, carefully monitored vitamin D treatment of high-risk patients will also result in a reduction of secondary hyperparathyroidism - or at least related to long-term complications such as osteomalacia, osteopenia/osteoporosis, bone and/ or muscle aches and pains and fractures. The FokI-polymorphism at the VDR gene is of clinical value in identifying female Turkish migrants who are at risk of decreased bone mineral density (osteopenia/osteoporosis). Furthermore, genetic predisposition for adult lactose intolerance is of high frequency (84.1\%) in Turkish immigrants but appears not to be a risk factor for an alteration of bone mineral density.

Thus, the results of this study reveal a unique osteogenetic pattern of a large group of migrated but ethnically homogeneous individuals in their new environment.

\section{Conflict of Interest: None.}

\section{Affiliations}

${ }^{1}$ Department of Internal Medicine and Rheumatology, Justus-LiebigUniversity Giessen, Department of Rheumatology, Clinical Immunology, Osteology and Physical Medicine, Kerckhoff-Klinik, Bad Nauheim, Germany ${ }^{2}$ Department of Cardiology, Kerckhoff-Klinik, Bad Nauheim, Germany

${ }^{3}$ Division of Endocrinology and Nuclear Medicine, Department of Internal Medicine, Medical University of Graz, Graz, Austria

${ }^{4}$ Division of Endocrinology, Diabetes and Metabolic Bone Disease,

Department of Internal Medicine, University of Dresden, Dresden, Germany

${ }^{5}$ Department of Clinical Chemistry and Laboratory Medicine, University of

Dresden, Dresden, Germany

${ }^{6}$ Department of Hemostasiology and Transfusion Medicine, Kerckhoff-Klinik, Bad Nauheim, Germany

Professorship of Rheumatology, Osteology and Physical Medicine,

Department of Internal Medicine, Justus-Liebig-University Giessen,

Department of Rheumatology, Clinical Immunology, Osteology and

Physical Medicine, Kerckhoff-Klinik, Bad Nauheim, Germany

\section{References}

1 Bartley J. Prevalence of vitamin D deficiency among patients attending a multidisciplinary tertiary pain clinic. N Z Med J 2008; 28: 57-62

2 Lips P. Vitamin D status and nutrition in Europe and Asia. J Steroid Biochem Mol Biol 2007; 103: 620-625

3 Gugatschka M, Dobnig H, Fahrleitner-Pammer A et al. Molecularlydefined lactose malabsorption, milk consumption and anthropometric differences in adult males. QJ Med 2005; 98: 857-863

4 Erkal MZ, Wilde J, Bilgin $Y$ et al. High prevalence of vitamin D deficiency, secondary hyperparathyreoidism and generalized bone pain in Turkish immigrants in Germany: identification of risk factors. Osteoporos Int 2006; 17: 1133-1140

5 Hintzpeter B, Scheidt-Naeve C, Müller MJ et al. Higher prevalence of vitamin $\mathrm{D}$ deficiency is associated with immigrant background among children and adolescents in Germany. J Nutr 2008; 138: 1482-1490

6 Holick MF. Vitamin D: A millenium perspective. J Cell Biochem 2003; 88: 296-307 
7 Holick MF. Vitamin D: importance in the prevention of cancers, type 1 diabetes, heart disease, and osteoporosis. Am J Clin Nutr 2004; 79: $362-371$

8 Meyer HE, Falch JA, Sogaard AJ et al. Vitamin D deficiency and secondary hyperparathyreoidism and the association with bone mineral density in persons with Pakistani and Norwegian background living in Oslo, Norway. The Oslo Health Study. Bone 2004; 35: 412-417

9 Francis RM, Selby PL. Osteomalacia. Baillières Clin Endocrinol Metabol 1997; 11: 145-163

10 Takeuchi Y. Pathophysiology in rickets/osteomalacia. Clin Calcium 2007; 17: 1508-1513

11 Obermayer-Pietsch BM, Lange U, Tauber $G$ et al. Vitamin D receptor initiation codon polymorphism, bone density and inflammatory activity of patients with ankylosing spondylitis. Osteoporos Int 2003; 14: 995-1000

12 Rizzoli R, Bonjour JP, Ferrari SL. Osteoporosis, genetics and hormones. J Mol Endocrinol 2001; 26: 79-94

13 Enattah N, Pekkarinen T, Välimäki MJ et al. Genetically defined adulttype hypolactasia and self-reported lactose intolerance as risk factors of osteoporosis in Finnish postmenopausal women. Eur J Clin Nutrition 2005; 59: 1105-1111

14 Enattah N, Pekkarinen T, Välimäki MJ et al. Calcium supply, bone mineral density and genetically defined lactose maldigestion in a cohort of elderly men. J Endocrinol Invest 2007; 30: 46-51

15 Obermayer-Pietsch BM, Gugatschka M, Reitter $S$ et al. Adult-type hypolactasia and calcium availability: decreased calcium intake or impaired calcium absorption? Osteoporos Int 2007; 18: 445-451

16 Obermayer-Pietsch BM, Bonelli CM, Walter DE et al. Genetic predisposition for Adult Lactose Intolerance and Relation to Diet, Bone Density, and Bone Fractures. J Bone Miner Res 2004; 19: 42-47
17 Gross C, Eccleshall TR, Malloy PJ et al. The presence of a polymorphism at the translation initiation site of the vitamin $\mathrm{D}$ receptor gene is associated with low bone mineral density in postmenopausal MexicanAmerican women. J Bone Miner Res 1996; 11: 1850-1855

18 Obermayer-Pietsch BM, Frühauf GE, Chararas $K$ et al. Association of the vitamin $\mathrm{D}$ receptor geneotype $\mathrm{BB}$ with low bone density in hyperthyroidism. J Bone Miner Res 2000; 15: 1950-1955

19 Maxwell JP, Pi HT, Liu HAC et al. Further studies in adult rickets (osteomalacia) and foetal rickets. Proc Roy Soc Med 1939; 32: 287-297

20 Albright $F$, Reifenstein $E$. The parathyroid glands and metabolic bone disease: selected studies. Baltimore: Williams \& Wilkins, 1948

21 Offermann G, Manhold C. Osteomalacia in Turkish Guest-Workers in Germany. Inn Med 1978; 5: 103-111

22 Chapuy MC, Arlot ME, Duboeuf $F$ et al. Vitamin D3 and calcium to prevent hip fractures in elderly women. N Engl J Med 1992; 327: 1637-1642

23 Wemeau JL. Calciotropic hormones and ageing. Horm Res 1995; 43: 76-79

24 Halleen JM. Tartrate-resistant acid phosphatase 5B is a specific and sensitive marker of bone resorption. Anticancer Res 2003; 23: 1027-1029

25 Delmas PD. Treatment of osteoporosis. Lancet 2002; 359: 2018-2026

26 Enattah NS, Sahi T, Savilahti $E$ et al. Identification of a variant associated with adult-type hypolactasia. Nat Genet 2002; 30: 233-237

27 Corazza GR, Benati G, Di Sario A et al. Lactose intolerance and bone mass in postmenopausal Italian women. Br J Nutr 1995; 73: 479-487 